INTERNACIONAL

\title{
Internamientos involuntarios y tratamientos forzados en psiquiatría: Autonomía y no discriminación como estándar de derechos humanos
}

\author{
Involuntary placement and forced treatment in psychiatry: \\ Autonomy and non-discrimination as a human rights standard
}

\author{
Francisca Figueroa San Martín \\ Pontificia Universidad Católica de Chile
}

\begin{abstract}
RESUMEN El artículo describe los actuales estándares de derechos humanos aplicables a las prácticas de internamiento involuntario y tratamiento forzado que se despliegan cotidianamente en el contexto psiquiátrico. Amparadas por la legalidad y el discurso terapéutico, permanecen vigentes en Chile y parte importante del mundo formas invisibilizadas de privación de libertad y sujeción de las personas a intervenciones altamente invasivas para su integridad física y psíquica en centros de salud mental, las que, en ausencia de un consentimiento libre e informado, constituyen una grave vulneración de los derechos reconocidos por la Convención sobre los Derechos de las Personas con Discapacidad. Se expondrá el contenido de aquellos estándares y las recientes recomendaciones para su implementación, a la luz de los pronunciamientos del Comité sobre los Derechos de las Personas con Discapacidad y el informe sobre integración en salud mental y derechos humanos, elaborado por el Alto Comisionado de Naciones Unidas para los Derechos Humanos.
\end{abstract}

PALABRAS CLAVE Autonomía, no discriminación, discapacidad, salud mental, psiquiatría.

ABSTRACT This article describes the current standards of human rights, applicable to involuntary placement and forced treatment practices that take place daily in the context of psychiatry. Protected by legality and a therapeutic discourse, there remain in Chile and in an important part of the world, invisible ways of deprivation of liberty and subjection of people to highly invasive interventions, affecting their physical and mental integrity in mental health centers, which in the absence of free and informed consent, constitute serious violations of the rights recognized by the Convention on the Rights of Persons with Disabilities. The content of those standards and recent recommendations 
on their implementation will be offered, in light of the comments made by the Committee on the Rights of Persons with Disabilities and the report about integration in Mental Health and Human Rights prepared by the United Nations High Commissioner for Human Rights.

KEYWORDS Autonomy, non-discrimination, disability, mental health, psychiatry.

\section{Planteamiento y metodología}

La Convención sobre los Derechos de las Personas con Discapacidad (CRPD) (Naciones Unidas, 2006a) constituye actualmente el más específico estándar de protección de derechos humanos respecto de las personas en situación de discapacidad mental o psicosocial. Fruto de un proceso de negociaciones inclusivo, que atendió desde la horizontalidad las voces de quienes han padecido la experiencia de la internación involuntaria y el tratamiento forzado en los dispositivos de salud mental (Palacios, 2008: 424), el instrumento tomó posición por la prohibición absoluta de aquellas prácticas coactivas que, amparadas en racionalidades decimonónicas de tutela y defensa social, se despliegan en ausencia del consentimiento libre y voluntario de la persona a quien afectan. De esta forma, dicha Convención ha promovido un cambio cultural basado en el reconocimiento de la dignidad, autonomía y no discriminación de las personas con discapacidad en la toma de decisiones respecto a su salud (Figueroa, 2017: 138).

Tales prácticas, que obedecen a un paradigma medicalizador respecto a la diversidad psíquica, el cual actualmente se encuentra cuestionado desde el enfoque de derechos humanos, son de tal afectación para la integridad de la persona que, cometidas sin su consentimiento libre y voluntario, constituyen actos de discriminación por motivos de discapacidad y abren paso a un debate de fondo respecto a su carácter de tortura, de conformidad al artículo 15 de la CRPD en relación al artículo 1 de la Convención contra la Tortura y otros Tratos o Penas Crueles, Inhumanos o Degradantes (CAT) (Naciones Unidas, 1984; Minkowitz, 2007: 413-426; Relator sobre la tortura y otros tratos o penas crueles, inhumanos o degradantes, 2008, 2013).

Previo a esta consideración, en el derecho internacional de los derechos humanos se encontraban permitidas tales prácticas. El ejemplo más claro son los Principios de protección de los enfermos mentales y el mejoramiento de la atención de la salud mental, adoptados por la Asamblea General de Naciones Unidas en 1991, que sirvieron de marco a la mayoría de las legislaciones en salud mental vigentes en el mundo (Organización Mundial de la Salud, 2006). En éstos se utiliza un lenguaje patologizador respecto a las afectaciones psicosociales, y si bien en su oportunidad constituyeron un avance al incorporar el derecho a defensa de la persona ante la internación psiquiátrica involuntaria - no implementado en Chile-, establecen mecanismos de sustitución de la voluntad que exceptúan el ejercicio de su derecho al consentimiento 
libre e informado a criterio médico. Es por este motivo que dichos estándares han sido sustituidos por aquellos contenidos en la CRPD en cuanto instrumento más avanzado de protección, de conformidad al principio de no regresividad en materia de derechos humanos (ACNUDH, 2007: párrafo 22).

Anclado en el reconocimiento de la autonomía y capacidad jurídica de la persona para la toma de decisiones en relación a su salud, y en una aplicación incondicional del principio de no discriminación, la CRPD abre paso a un cambio de paradigma en el derecho internacional de los derechos humanos, pues prohíbe de forma absoluta por discriminatoria la privación de libertad por motivos de discapacidad, aun cuando tal condición se considere asociada a otros factores, como la necesidad de cuidado o el riesgo de daño a sí mismo o terceros. De igual forma, prohíbe la aplicación de tratamientos forzados o no consentidos en el contexto del internamiento psiquiátrico (Comité sobre los Derechos de las Personas con Discapacidad, 2015: párrafo 11), con el objetivo de resguardar la autonomía e integridad física y psíquica de la persona.

Revisados antecedentes documentales respecto a la emergencia de los estándares de la CRPD en materia de salud mental, y su actual fenómeno de expansión y difusión por parte de las agencias de Naciones Unidas, se expondrán los recientes lineamientos para su implementación, con el objetivo de contribuir a su comprensión y promover directrices que faciliten el proceso de armonización de leyes y políticas públicas en el ámbito local.

\section{Autonomía y no discriminación, el amparo normativo contenido en la CRPD}

El derecho de toda persona al disfrute del más alto nivel posible de salud física y mental, reconocido en el artículo 12 del Pacto Internacional de Derechos Económicos, Sociales y Culturales (Naciones Unidas, 1996), contiene tanto una dimensión asociada al acceso a los servicios, como una esfera de libertades. Lo último contempla el derecho a la libertad para decidir sobre la propia salud y cuerpo, libre de interferencias, tortura e intervenciones médicas no consentidas (Comité sobre los Derechos de las Personas con Discapacidad, 2013: párrafo 37; ACNUDH, 2017: párrafo 7). Tal contenido se recoge indubitadamente por la CRPD al reconocer en el artículo 12 el igual reconocimiento como persona ante la ley, que encuentra en este ámbito aplicación concreta en el ejercicio del derecho al consentimiento libre e informado, contenido en el artículo 25 del instrumento, que resguarda el derecho a la salud sin discriminación por motivos de discapacidad.

Si bien la CRPD se enmarca en la protección de las personas con discapacidad —entendida ésta desde el modelo social-, conforme se pronunció recientemente el Alto Comisionado de Naciones Unidas para los Derechos Humanos (ACNUDH) en su informe de integración de derechos humanos y salud mental, tal marco de protección de derechos humanos debe aplicarse sin distinción tanto a personas con 
discapacidades psicosociales, como respecto de personas que, sin encontrarse en tal situación, son usuarias de los servicios de salud mental o padecen alguna condición de salud mental (ACNUDH, 2017: párrafo 5).

Gracias a que comprende la salud mental no sólo como un asunto de carácter médico o científico, sino como un asunto de derechos humanos, dignidad y justicia social, en que se encuentran implicadas las condicionantes de exclusión y precariedad que dan paso a la aflicción psicoemocional en las personas y la construcción de la discapacidad en su contexto (ACNUDH, 2017: párrafos 12-14, 34), el actual posicionamiento de la CRPD es reconocido como el más avanzado estándar de derechos humanos en la materia (ACNUDH, 2017: párrafo 22). Abre cuestionamientos de fondo a las prácticas de internamiento involuntario y tratamiento forzado que se despliegan en los dispositivos de psiquiatría, insta a su abolición (Comité sobre los Derechos de las Personas con Discapacidad, 2015: párrafo 10; ACNUDH, 2017: párrafo 42) y las coloca dentro del marco jurídico específico sobre privación de libertad, entendida ésta como «cualquier forma de detención o encarcelamiento o de custodia de una persona por orden de una autoridad judicial o administrativa o de otra autoridad pública, en una institución pública o privada de la cual no pueda salir libremente» (Naciones Unidas, 2006b: artículo 4).

El artículo 14 de la CRPD resguarda el derecho a la libertad y seguridad de la persona, esto es, el derecho a la libertad respecto al confinamiento del cuerpo y respecto a lesiones que comprometan la integridad física y mental de la persona en tal contexto (ACNUDH, 2017: párrafo 31). Como bien ha señalado el Comité sobre los Derechos de las Personas con Discapacidad (2015: párrafo 4), ésta es en esencia una disposición de no discriminación, que prohíbe de forma indubitada la privación de libertad por motivos de discapacidad, esté o no considerada en combinación a otros factores. Este estándar es el que actualmente permite observar críticamente las prácticas de internación involuntaria e institucionalización en psiquiatría, así como los tratamientos que tienen lugar en tal contexto y en ausencia del consentimiento libre e informado, pues las prohíbe de forma categórica y dispone su equivalencia a la privación de libertad arbitraria (Comité sobre los Derechos de las Personas, 2015: párrafo 6).

De igual forma se aplican, respecto al tratamiento forzado, las normas contenidas en los artículos 15 sobre protección contra la tortura, 16 sobre protección contra la explotación, violencia y abuso, y 17 sobre protección a la integridad personal. Esto dado que, como ha señalado el Comité y ACNUDH, el tratamiento forzado y otras prácticas como el aislamiento ${ }^{1}$, el uso de contenciones físicas y farmacológicas y la

1. Respecto a este punto, la Declaración de Estambul sobre la utilización y los efectos de la reclusión en régimen de aislamiento prohíbe totalmente su uso en personas con padecimientos mentales. Véase el Anexo 1 en Relator sobre la tortura y otros tratos o penas crueles, inhumanos o degradantes (2008). 
sobremedicación no sólo violan el artículo 25 de la CRPD, sino que representan derechamente malos tratos y pueden llegar a constituir tortura, por lo que se insta a su abolición y la articulación de mecanismos que favorezcan el ejercicio del consentimiento libre e informado en los servicios de salud mental, sin excepción (Comité sobre los Derechos de Personas con Discapacidad, 2013: párrafo 38; 2015, párrafo 12; ACNUDH, 2017: párrafo 33).

Por tanto, aún en el evento de que una persona se encuentre en situación de crisis, vea disminuida su capacidad mental en un caso concreto o se encuentre en una situación en que sea difícil determinar su voluntad, los agentes de los servicios de salud deben abstenerse de sustituir la voluntad de la persona por el criterio médico o de familiares, ajustados a la consideración de la «mejor interpretación de la voluntad y preferencias de la persona», en reemplazo del criterio del «interés superior» (Comité sobre los Derechos de Personas con Discapacidad, 2015: 22-23; ACNUDH, 2017: párrafo 28).

El actual estándar es de fondo. No consiste en la articulación de resguardos procesales para habilitar la intervención psiquiátrica coactiva, sino en su prohibición absoluta, por constituir una vulneración a la dignidad, libertad e integridad de la persona. Tal compromiso no implica en caso alguno la desatención de la persona en el ámbito de su salud; por el contrario, promueve el ejercicio de derechos y su empoderamiento en la experiencia de recuperación. Sobre este punto, el Comité ha referido:

Históricamente, a las personas con discapacidad se les ha negado en muchas esferas de una manera discriminatoria su derecho a la capacidad jurídica, en virtud de regímenes basados en la sustitución en la adopción de decisiones como la legislación sobre la salud mental, la tutela y la custodia que permiten el tratamiento obligatorio. Esas prácticas deben ser abolidas, a fin de que las personas con discapacidad recobren la plena capacidad jurídica en igualdad de condiciones con las demás (Comité sobre los Derechos de las Personas con Discapacidad, 2013: párrafo 7).

\section{El fin de la coacción en salud mental, lineamientos iniciales para su implementación}

La implementación de los desafíos contenidos en la CRPD implica un posicionamiento ético profundo por la igualdad de derechos, no discriminación y legítima diversidad respecto de quienes padecen la discapacidad psicosocial. En pleno siglo $\mathrm{XXI}$, el instrumento adopta un enfoque de vanguardia desde la óptica del modelo social, que entiende la discapacidad como:

Un concepto que evoluciona y que resulta de la interacción entre las personas con deficiencias y las barreras debidas a la actitud y al entorno que evitan su participación plena y efectiva en la sociedad, en igualdad de condiciones con las demás (CRPD, preámbulo, letra 3 ). 
Esta consideración se hace en contraposición al anterior modelo biomédico-rehabilitador de corte decimonónico, en que la discapacidad se entendía como una enfermedad del sujeto que la padece, respecto de quien deben operar los mecanismos de normalización desarrollados por las disciplinas médicas (Palacios, 2008: 67).

Es precisamente en el contexto psiquiátrico en el que aquella consideración se torna especialmente relevante, por cuanto la patologización de la diversidad y malestar psicoemocional habilita una radical asimetría entre las voces terapéuticas y las de quienes son diagnosticados. El Relator sobre la tortura y otros tratos o penas crueles, inhumanos o degradantes refiere esta circunstancia como una desigualdad estructural que habilita terreno a la tortura y malos tratos en el contexto hospitalario, por cuanto:

El desequilibrio en las relaciones de poder entre médicos y pacientes, agravadas por el estigma y la discriminación, hace que las personas de determinados grupos se vean, de forma desproporcionada, en la tesitura de no poder ejercer su derecho al consentimiento informado (Relator sobre tortura y otros tratos o penas crueles, inhumanos o degradantes, 2013: párrafo 29).

Esto los priva de su capacidad jurídica al despojarla de su derecho a tomar decisiones.

Compartiendo la postura de la CRPD y reconociendo sus estándares como frutos de un cambio de paradigma socionormativo, en el cual han sido protagonistas las propias voces del movimiento de usuarios y sobrevivientes de la psiquiatría (Palacios, 2008: 424; Figueroa, 2017: 128), se presentarán algunos lineamientos para su implementación entregados recientemente tanto por el Comité sobre los Derechos de las Personas con Discapacidad como por ACNUDH en su informe de integración sobre salud mental y derechos humanos.

En términos generales, se pone de manifiesto la necesidad de generar cambios de fondo, cambios culturales, normativos, de políticas públicas, anclados en el reconocimiento de la autodeterminación e igualdad de derechos de las personas con afectaciones de salud mental (ACNUDH, 2017: párrafo 34), incluyendo niños y niñas. De esta forma, se vuelve esencial la participación de las personas a quienes las prácticas de los servicios de salud mental afectan, cuyas voces deben ser determinantes en la elaboración de políticas públicas que propendan a la implementación de la CRPD en los ámbitos locales, para lo cual el Estado de ejercer un rol de promoción y fortalecimiento de la sociedad civil (ACNUDH, 2017: párrafos 43-44).

Tanto el Comité como ACNUDH han instado a los Estados a revisar la legislación interna de acuerdo con una cabal comprensión de los estándares de la CRPD, por lo que han recomendado evitar políticas públicas que los disminuyan (ACNUDH, 2017: párrafos 23, 28), derogar las leyes que establecen discriminaciones a las personas por motivos de salud mental (ACNUDH, 2017: párrafo 39) y atender a los determinantes 
sociales que contribuyen a la construcción de la discapacidad en el ámbito psicosocial, con enfoque intersectorial y de género (ACNUDH, 2017: párrafo 40).

Se insta a articular políticas tendientes a disminuir el estigma y discriminación que sufren las personas con afectaciones de salud mental, a proteger a la persona del internamiento involuntario y tratamiento forzado favoreciendo el ejercicio de su derecho al consentimiento libre e informado, prohibiendo toda forma de sustitución de su voluntad y asegurando disponibilidad y acceso igualitario a los servicios de apoyo para las personas con afectaciones de salud mental. Estas políticas deben incluir en su cobertura a quienes se encuentran en prisiones u otros recintos de detención, $y$ asegurar el acceso a la justicia en el caso de ser víctimas de violaciones de derechos humanos en tal contexto (ACNUDH, 2017: párrafo 41).

En cuanto a la legislación en salud mental, se recomienda que ésta no aborde aspectos relacionados con la capacidad jurídica ni con el derecho a la libertad y seguridad, pues tales ámbitos deben regularse en conformidad con la normativa general aplicable a todas las personas. Se insta a prohibir la privación de libertad basada en la discapacidad o afectación de salud mental, lo que incluye aquellos casos en que se invoca la necesidad de tratamiento o posible peligro para sí o terceros, asegurando el ejercicio del consentimiento libre e informado en todos los casos mediante ajustes de accesibilidad en la información. Así mismo, los Estados deben adoptar un marco legal de apoyo en la toma de decisiones, uno que promueva herramientas como las declaraciones de voluntad anticipadas y el uso del criterio de «la mejor interpretación de la voluntad y preferencias de la persona», en caso de no poder determinarse el contenido de su voluntad (ACNUDH, 2017: párrafos 28, 42).

En cuanto al gasto público en salud mental, se realiza un importante cuestionamiento al advertir que los países cuentan con un escaso presupuesto asignado a tal ítem, destinado principalmente al financiamiento de hospitales psiquiátricos e instituciones asociadas a graves vulneraciones de derechos humanos. En esta línea, se insta a detener la inyección de recursos públicos en el modelo manicomial y sus prácticas, y propender a su supresión redireccionando el financiamiento a políticas sociales que tiendan al ejercicio efectivo y sin discriminación de los derechos económicos, sociales y culturales.

Debe fortalecerse la investigación científica en el ámbito de la salud mental, a través de la promoción de enfoques desmedicalizadores, como son las técnicas de acompañamiento no coactivas sobre la base de grupos de apoyo mutuo y otras metodologías de diálogo abierto y horizontal que centran los procesos de recuperación de las personas en la intervención comunitaria (ACNUDH, 2017: párrafos 51, 54).

Se debe prohibir la institucionalización forzada en dispositivos de salud mental y promover el ejercicio del derecho a vivir de forma independiente y ser incluido en la comunidad, contenido en el artículo 19 de la CRPD (ACNUDH, 2017: párrafos 11, 19, 20, 45-46, 59), mediante la implementación de políticas de desinstitucionalización 
que garanticen un acceso a la asistencia, a cuidados sanitarios, a sistemas de respuesta a las crisis, a grupos de apoyo al interior de la comunidad y a alojamiento en situaciones de emergencia, entre otras (ACNUDH, 2017: párrafo 57).

En relación con la especial situación de salud mental en niños y niñas, se advierte a los Estados que la institucionalización causa importantes daños, al estar asociada a formas de violencia y abuso, por lo que debe propenderse a su fin independiente de si están o no en situación de discapacidad, con el objetivo de resguardar su derecho a vivir en la comunidad y tener una familia (ACNUDH, 2017: párrafo 58).

Por último, el Comité ha instado a la implementación de mecanismos independientes de observación y monitoreo a las instituciones psiquiátricas, con el objetivo de que, contando con participación de la sociedad civil, ejerzan labores de supervisión y revisión a las internaciones involuntarias, sin que esto implique su aceptación (Comité sobre los Derechos de las Personas con Discapacidad, 2015: párrafo 19). Sobre este punto, tal labor de monitoreo debe contemplar instrumentos específicos y adecuados a los estándares de la CRPD, así como observadores capacitados en tal enfoque, con el objeto de identificar las prácticas de tortura y malos tratos presentes en el contexto hospitalario (Asociación para la Prevención de la Tortura, 2016: 39-41). En éste, el discurso terapéutico es utilizado desde la verticalidad para justificar la sujeción y control de las personas privadas de libertad mediante el uso de contenciones físicas y químicas, aislamiento y procedimientos de gran afectación para su integridad, los que en algunos casos llegan a tener efectos irreversibles, lo cuales causan graves sufrimientos físicos y mentales en quienes los padecen (FRA, 2012: 42, 44).

En tal ámbito de encierro, junto a la posibilidad de eventualmente advertir formas de castigo, intimidación o coacción, encontramos que aun desplegándose tales prácticas sobre la base de una justificación terapéutica, la circunstancia de negar a la persona el ejercicio de su derecho al consentimiento libre e informado en la toma de decisiones, negar la accesibilidad en la información para tomar cabal conocimiento de los riesgos asociados a los tratamientos propuestos, negar el acceso a apoyos para decidir y el no establecimiento de salvaguardias que cautelen que en su decisión no han mediado injerencias indebidas, constituye una evidente discriminación por motivo de discapacidad que vulnera los derechos reconocidos en los artículos 12, 14, 15 y 25 de la CRPD, y habilita espacio al análisis de tales circunstancias bajo el enfoque de la CAT (Relator sobre la tortura y otros tratos o penas crueles, inhumanos o degradantes, 2008: párrafos 45-51; 2013: párrafos 17-22). Por su parte, el artículo 15 de la CRPD extiende literalmente la protección de la persona respecto a experimentos médicos o científicos, por lo que prohíbe su realización sin libre consentimiento. Todo lo cual implica necesariamente que los instrumentos de monitoreo de tortura y malos tratos aplicables a las instituciones psiquiátricas deben contar con una arista específica de observación a la internación involuntaria, tratamiento forzado y experimentación en personas con discapacidades psicosociales, para adecuar la observación de tales cir- 
cunstancias en conformidad con los estándares contenidos en la CRPD y promover la implementación de los mismos mediante la visibilización de tales prácticas en su tan cuestionada dimensión.

\section{Conclusiones}

La Convención sobre los Derechos de las Personas con Discapacidad constituye el marco normativo más avanzado y específico en materia de protección de derechos humanos respecto de las personas con discapacidad psicosocial o usuarias de los servicios de salud mental y psiquiatría.

Tal instrumento constituye un cambio de paradigma en la forma de abordar la discapacidad, pues toma posición por una comprensión social de aquella condición mediante el reconocimiento de la diversidad psíquica como parte de la diversidad humana, con lo cual abandona el estigma de enfermedad, peligrosidad e incapacidad en que se anclan las prácticas de internación involuntaria y tratamiento forzado en el contexto psiquiátrico, las que gozan de lamentable actualidad en Chile y el mundo.

En lo medular, el actual estándar de derechos humanos prohíbe de forma absoluta la privación de libertad por motivos de discapacidad, por lo que insta al reconocimiento de la capacidad jurídica de la persona en lo que respecta a la toma de decisiones en materia de salud, a la disponibilidad y accesibilidad en la información para hacerla efectiva, al establecimiento de mecanismos de apoyo para el ejercicio de tal voluntad mediante el consentimiento libre e informado respecto de todas y cada una de las prácticas que puedan afectarle, así como al instauración de salvaguardias que cautelen su voluntad y preferencias.

Los actuales estándares de derechos humanos nos muestran que las prácticas de internamiento involuntario y tratamiento forzado que se despliegan en los contextos hospitalarios de salud mental deben derechamente abolirse, por cuanto constituyen discriminaciones por motivos de discapacidad, equivalen a la privación de libertad arbitraria y, en la medida en que cumplan con los estándares establecidos en la CAT, pueden dar lugar además a su calificación como tortura.

Para efecto de su implementación, las agencias de las Naciones Unidas se encuentran en proceso de generar lineamientos y directrices que permitan a los Estados avanzar hacia la erradicación de las prácticas coactivas en el ámbito psiquiátrico, y a la configuración de políticas sociales de desinstitucionalización y acceso a la salud con un enfoque de derechos humanos, de acompanamiento desmedicalizador, horizontal y comunitario, que centre su atención en los determinantes sociales que se implican en los estados de aflicción de las personas y la configuración de la discapacidad psicosocial en su contexto. 


\section{Referencias}

ACNUDH, Alto Comisionado de las Naciones Unidas para los Derechos Humanos (2017). «Mental health and human rights». A/HRC/34/32.

Asociación para la Prevención de la Tortura (2016). Monitoring psychiatric institutions. Outcome report. Ginebra: Asociación para la Prevención de la Tortura, 39-41. Disponible en http://bit.ly/2kwaucY.

Comité sobre los Derechos de las Personas con Discapacidad (2013). Observación general sobre el artículo 12: Igual reconocimiento como persona ante la ley. $\mathrm{CRPD} / \mathrm{C} / 11 / 4$.

-. (2015). Guidelines on article 14 of the Convention on the Rights of Persons with Disabilities. The right to liberty and security of persons with disabilities. Ginebra: Comité sobre los Derechos de las Personas con Discapacidad.

Figueroa, Francisca (2017). «Voces de usuarios y sobrevivientes de la psiquiatría contenidas en la Convención sobre los Derechos de las Personas con Discapacidad. Un nuevo paradigma abre camino en Chile». Revista Latinoamericana en Discapacidad, Sociedad y Derechos Humanos, 1 (1): 123-142. Disponible en http:// bit.ly/2vwccxm.

FRA, Agencia de la Unión Europea para los Derechos Fundamentales (2012). Involuntary placement and involuntary treatment of persons with mental health problems. Viena: Agencia de la Unión Europea para los Derechos Fundamentales.

Minkowitz, Tina (2007). «The United Nations Convention on the Rights of Persons with Disabilities and the right to be free from nonconsensual psychiatric interventions». Syracuse Journal of International Law and Commerce, 34 (2): 405-428. Disponible en http://bit.ly/2vMiMiO.

Naciones Unidas (1966). Pacto Internacional de Derechos Económicos, Sociales y Culturales. Adoptada el 16 de diciembre de 1966.

-. (1984). Convención contra la tortura y otros tratos o penas crueles, inhumanos o degradantes. Adoptada el 10 de diciembre de 1984.

-. (1991). Principios para la protección de los enfermos mentales y el mejoramiento de la atención de la salud mental. Adoptada el 17 de diciembre de 1991.

-. (2006a). Convención sobre los Derechos de las Personas con Discapacidad. Adoptada el 13 de diciembre de 2006.

-. (2006b). Protocolo Facultativo de la Convención contra la Tortura y otros Tratoso Penas Crueles, Inhumanos o Degradantes. Adoptado el 22 de junio de 2006.

Organización Mundial de la SAlud (2006). Manual de recursos de la OMS sobre salud mental, derechos humanos y legislación. 1. ${ }^{\mathrm{a}}$ ed. Ginebra: Organización Mundial de la Salud. Disponible en: http://bit.ly/1ys6t4b.

Palacios, Agustina (2008). El modelo social de discapacidad. Orígenes, caracteriza- 
ción y plasmación en la Convención Internacional sobre los Derechos de las Personas con Discapacidad. 1. ${ }^{\mathrm{a}}$ ed. Madrid: Cinca.

RELATOR SOBRE LA TORTURA Y OTROS TRATOS O PENAS CRUELES, INHUMANOS O DEGRADANTES (2008). Informe provisional del relator sobre la tortura y otros tratos o penas crueles, inhumanos o degradantes. A/63/175.

-. (2013) Informe del relator sobre la tortura y otros tratos o penas crueles, inhumanos o degradantes. A/HRC/22/53.

\section{Sobre la autora}

Francisca Figueroa San Martín es abogada. Licenciada en Derecho de la Pontificia Universidad Católica de Chile. Máster en Criminología, Política Criminal y Sociología Jurídico-Penal de la Universidad de Barcelona, y máster en Derecho Penal de la Universidad de Sevilla. Leasur ONG, Santiago de Chile. Su correo electrónico es franciscafsm@gmail.com. 
